Research Article

\title{
Examination of causes behind procrastination among Shahrekord University of Medical Sciences employees and proposing some strategies for their preventing: A study using the Van Wyk's Model
}

\author{
Mohsen Khaksar Boldaji ${ }^{1}$, Alireza Shirvani ${ }^{2}$, Javad Sharifi-Rad ${ }^{3,4}$, Hamid Raeisi ${ }^{1}$, \\ Ali Akbar Rastar ${ }^{1}$, Razieh Mirzaeian ${ }^{1 *}$
}

\begin{abstract}
${ }^{1}$ Ph.D Student Health Information Management, Deputy of Research and Technology, Shahrekord University of Medical Sciences, Shahrekord, Iran 2Islamic Azad University, Branch of Dehaghan, Isfahan, Iran

${ }^{3}$ Zabol Medicinal Plants Research Center, Zabol University of Medical Sciences, Zabol, Iran

${ }^{4}$ Department of Pharmacognosy, Faculty of Pharmacy, Zabol University of Medical Sciences, Zabol, Iran
\end{abstract}

Received: 06 May 2015

Accepted: 05 June 2015

\section{*Correspondence:}

Dr. Razieh Mirzaeian,

E-mail: rmirzaeian@yahoo.com

Copyright: (C) the author(s), publisher and licensee Medip Academy. This is an open-access article distributed under the terms of the Creative Commons Attribution Non-Commercial License, which permits unrestricted non-commercial use, distribution, and reproduction in any medium, provided the original work is properly cited.

\begin{abstract}
Background: Competition among the organizations and enterprises plays a particularly important role in the gathering of the profits and acquisition of internal and external resources. Procrastination is one of the main barriers to efforts made towards increasing the productivity and efficiency in the organizations. Accordingly, the main goal of this research was to explore the reasons of procrastination among the employees based on Van Wyk's model and present some strategies for preventing it.

Methods: Descriptive-analytical in nature, this study was conducted on a sample of 200 employees selected from Shahrekord University of Medical Sciences using a self-designed checklist developed based on the informational components incorporated in the Van Wyk's model. This model consists of 9 factors affecting the level of procrastination observed among the employees i.e. resistance, boredom, perfectionism, last-minute syndrome, lack of motivation for a task, fear of failure, skill deficit, rebelliousness and disorganization. The validity of the developed checklist was checked using its assessment by the expert professors and its reliability was measured with Cronbach's alpha. Both of them were confirmed (Cronbach's alpha of 90\%). To analyze the data, T-test and variance analysis were used.

Results: The results of the study showed that there was a statistically significant relationship between employee's resistance, boredom, perfectionism and lack of motivation for task and procrastination $(\mathrm{p}=0.001)$; however, the association between fear of failure, rebelliousness and disorganization and procrastination was not statistically significant $(\mathrm{p}=0.871)$.

Conclusions: The availability of high quality organizational capital will enhance the chance of organization's success, survival and advancement. As a result, identifying the attributes of human resources and the factors influencing their efficiency so as to exploit the human capital more optimally and remove the reasons of procrastination is of high significance.
\end{abstract}

Keywords: Planning, Procrastination, Employee's procrastination, Organization, Van Wyk's model

\section{INTRODUCTION}

Man feels an eternal need to change the status quo in order to adapt to the external changes. Under such circumstances, the speed of reaction plays a determining role in the individual and organizational efficacy and effectiveness so that managing the time properly and performing the tasks timely will be a necessity at both 
individual and organizational level. ${ }^{1,2}$ Human resources are one of the significant organizational capitals playing a key part in the fulfillment of the organization's goals. If an organization has access to the best technologies but lacks the professional and efficient labor force and fails to best utilize their capabilities, it may not be capable of affecting the environment or compete successfully. However, unfortunately, the organizations and institutions have not pay due consideration to the procrastination problem. Procrastination or putting off the tasks to a future time is so common that it can be deemed as one of the human's intrinsic inclinations. ${ }^{3-6}$ As researchers argue, procrastination is a specific trait covering cognitive, motivational and behavioral dimensions which results in wasted time, poor performance and heightened stress at the workplace..$^{7-9}$ Sometimes, the procrastinators get themselves ready for completing the task but evade its completion. ${ }^{10}$ The procrastinators can be divided into two subcategories, namely, passive and active procrastinators. Passive procrastinators suspend their tasks due to their indecision and the past failure to completing their tasks on time. On the contrary, the active procrastinators prefer to work under pressure and make deliberate decisions for postponing their assigned tasks. However, they usually perform their tasks on time. ${ }^{11}$ Lee distinguishes between two sorts of procrastination behaviors i.e. optimistic vs. pessimistic procrastinators. The optimistic procrastinators put off their intentions without any worry about it since they are confident about their final success. On the contrary, the pessimistic procrastinators are worry about their delay. However, they still procrastinate because they do not know how to handle their tasks. ${ }^{12}$ Different theories have been proposed for procrastination. Traditional psychodynamic theories regard procrastination as a symbolic return to the childhood's psychological and physical conflicts. ${ }^{13}$ Some reasons why the employees show tendency to resort to procrastination are as follows: resistance, boredom due to repetitive works, perfectionism, last-minute syndrome, lack of motivation for task, fair of failure, skill deficit, rebelliousness, disorganization. ${ }^{14,10,15}$ Overcoming the procrastination would bring psychological relief, pleasant feeling, increased individual's control over the conditions, feeling relaxed and freedom, feeling being fit and competent, feeling tranquility and the termination of stress and tensions. ${ }^{16}$ The negative effects of procrastination on the mental health are stress, anxiety and depression. ${ }^{17}$ The other consequences are lack of concentration, fear and worry, communicative problems and weak performance. ${ }^{18}$ Therefore, the higher the quality of this organizational capital is, the higher the possibility of success, survival and progress of the organization is. Taking all these into consideration, this study tried to shed some light on the characteristics of labor force and the factors influencing their efficiency so as to allow the exploitation of this organizational capital in a better way and rub out the root causes behind procrastination aimed at promoting the quality of organization performance.

\section{METHODS}

This descriptive-analytical study was conducted using cross-sectional method. Research population included all the employees of Shahrekord University of Medical Sciences. Given the population size, a sample consisting of 200 people were proportionally selected using stratified and systematic random sampling methods from the samples units. To explore the reasons of procrastination among the employees, a self-designed checklist developed based on Van Wyk's model was used. The items included in this questionnaire were as follows: demographic information (5 items), the factors related to procrastination i.e. resistance (5 items), boredom (4 items), perfectionism (4 items), last-minute syndrome ( 5 items), lack of motivation for task ( 5 items), fear of failure (4 items), lack of skill (4 items), rebelliousness (5 items), disorganization (4 items) scored based on a Likert scale. A number of respective professors and experts in the Management Sciences domain checked the validity of the designed checklist and confirmed it. After the collection of the completed questionnaires forms, its validity and reliability were confirmed by estimating Cronbach alpha (90\%). The collected data were put into SPSS 13 software to be analyzed using independent T-test and variance analysis techniques.

\section{RESULTS}

The results of demographic information related to the population in question revealed that among 2000 employees in the Shahrekord University of Medical Sciences, the number of male and female respondents were $48.5 \%$ (97 subjects) and 51.5\% (103), respectively. In terms of age, the highest frequency was found for the age range of $35-45$ year old $(37 \%=74$ subjects $)$ while the highest frequency for the level of study was B.A. degree $(57 \%=114$ subjects $)$, the highest frequency for the employment history was reported for the period under 5 years $28.5 \%$ (57). Finally, the highest frequency in terms of job categories was observed for the health-care personnel ( $48 \%=96$ subjects). (Table 1$)$

As far as the relationship between employee's procrastination and resistance is concerned, based on the findings, it can be inferred that there was a statistically significant correlation between resistance and procrastination mean scores $(\mathrm{p}<0.0001)$. In addition, the mean scores for the boredom were significantly related to procrastination $(\mathrm{p}<0.001)$. Therefore, it can be said that boredom has a role in the occurrence of procrastination. The mean scores obtained for employees' perfectionism, last-minute syndrome revealed that they have a statistically significant relationship with procrastination $(\mathrm{p}<0.001)$. Hence, it can be concluded that perfectionism trait and last-minute syndrome play a part in the procrastination observed for the employees under research. 
As for lack of motivation for task and procrastination, the mean scores obtained indicated that they were significantly related $(\mathrm{p}<0.001)$. Hence, this factor has also a role in the occurrence of procrastination. With respect to the association between the skill deficit and procrastination, it was found that there was a statistically significant relationship between them. Again, it can be summed up that skill deficit has a role in the procrastination. However, the fear of failure, employees' rebelliousness and disorganization scales yielded completely different results reporting no statistically significant association between these factors and employees' procrastination ( $\mathrm{p}=0.87$ for fear of failure, $\mathrm{p}=0.68$ for skill deficit and $\mathrm{p}=0.43$ for rebelliousness) (Table 2).

In terms of the association between the various factors of procrastination and gender and age variables, no statistically significant difference was observed ( $p>0.05)$.

As it is clear from Table 3, no difference was observed between male and female for any factors of employees' procrastination $(\mathrm{p}>0.05)$ (Table 3$)$.

Table1: The frequency distributions gained for the employees under research in terms of age, level of education, employment history and job category.

\begin{tabular}{|c|c|c|c|c|c|}
\hline Age & Frequency & Percentage & Level of Education & Frequency & Percentage \\
\hline Under 25 & 16 & $8.0 \%$ & $\begin{array}{l}\text { Associate of Arts degree } \\
\text { (A.A.) and Lower }\end{array}$ & 47 & $23.5 \%$ \\
\hline $25-35$ & 71 & $35.5 \%$ & Bachelor of Arts (B.A.) & 114 & $57.0 \%$ \\
\hline $35-25$ & 74 & $37.0 \%$ & $\begin{array}{l}\text { Master of Arts } \\
\text { (M.A.) and Higher }\end{array}$ & 39 & $19.5 \%$ \\
\hline Over 45 & 39 & $19.5 \%$ & Total & 200 & 100 \\
\hline Total & 200 & 100 & Job Category & Frequency & Percentage \\
\hline $\begin{array}{l}\text { Employment } \\
\text { history }\end{array}$ & Frequency & Percentage & Administrative-Financial & 65 & $32.5 \%$ \\
\hline Under 5 years & 57 & 28.5 & Health-Care & 96 & $48.0 \%$ \\
\hline $5-10$ years & 37 & 18.5 & Training-Cultural & 10 & $5.0 \%$ \\
\hline 10-15 years & 25 & 12.5 & Information Technology & 6 & $3.0 \%$ \\
\hline $15-20$ years & 25 & 12.5 & Services & 8 & $4.0 \%$ \\
\hline Over 20 years & 56 & 28.0 & Social Affairs & 6 & $3.0 \%$ \\
\hline Total & 200 & 100.0 & Technical-Engineering & 9 & $4.5 \%$ \\
\hline
\end{tabular}

Table 2: The comparison of the mean scores obtained for the variables of the employees' procrastination and the standard mean scores based on the statistical test.

\begin{tabular}{|l|llll|l|}
\hline & $\begin{array}{l}\text { Standard } \\
\text { mean }\end{array}$ & $\begin{array}{l}\text { Mean } \\
\text { score } \pm \text { SD }\end{array}$ & $\begin{array}{l}\text { Test } \\
\text { statistic }\end{array}$ & $\begin{array}{l}\text { Degree of } \\
\text { freedom }\end{array}$ & P value \\
\hline Employees' resistance & 3 & $4.03 \pm 0.71$ & 20.27 & 199 & 0.00 \\
\hline Boredom & 3 & $3.92 \pm 0.66$ & 19.58 & 199 & 0.00 \\
\hline Perfectionism & 3 & $3.92 \pm 0.66$ & 20.27 & 199 & 0.00 \\
\hline Last minute syndrome & 3 & $3.22 \pm 0.66$ & 3.39 & 199 & 0.001 \\
\hline Lack of motivation for task & 3 & $4.28 \pm 0.59$ & 30.56 & 199 & 0.00 \\
\hline Fear of failure & 3 & $3.01 \pm 0.86$ & 0.163 & 199 & 0.871 \\
\hline Skill deficit & 3 & $3.77 \pm 0.60$ & 18.17 & 199 & 0.00 \\
\hline Rebelliousness & 3 & $3.05 \pm 0.69$ & 1.29 & 199 & 0.68 \\
\hline Disorganization & 3 & $2.94 \pm 0.89$ & 1.79 & 199 & 0.43 \\
\hline
\end{tabular}

Table 3: The comparison of between male and female for any factors of employees' procrastination.

\begin{tabular}{|l|lllll|l|}
\hline \multirow{2}{*}{ Resistance } & Gender & frequency & Mean score \pm SD & Test statistic & P value \\
\hline & Female & 16 & $3.81 \pm 0.75$ & -0.817 & 0.41 \\
\cline { 2 - 7 } & Male & 71 & $3.97 \pm 0.72$ & -1.269 & 0.20 \\
\hline
\end{tabular}




\begin{tabular}{|c|c|c|c|c|c|}
\hline & Male & 71 & $4 \pm 0.67$ & & \\
\hline \multirow{2}{*}{ Perfectionism } & Female & 16 & $3.90 \pm 0.86$ & \multirow{2}{*}{-0.028} & \multirow{2}{*}{0.97} \\
\hline & Male & 71 & $3.91 \pm 0.72$ & & \\
\hline \multirow{2}{*}{ Last-minute syndrome } & Female & 16 & $3.47 \pm 1.01$ & \multirow{2}{*}{0.774} & \multirow{2}{*}{0.44} \\
\hline & Male & 71 & $3.26 \pm 0.95$ & & \\
\hline \multirow{2}{*}{ Lack of motivation for task } & Female & 16 & $4.13 \pm 0.72$ & \multirow{2}{*}{-0.802} & \multirow{2}{*}{0.42} \\
\hline & Male & 71 & $4.28 \pm 0.66$ & & \\
\hline \multirow{2}{*}{ Fear of failure } & Female & 16 & $3.12 \pm 0.82$ & \multirow{2}{*}{0.620} & \multirow{2}{*}{0.53} \\
\hline & Male & 71 & $2.98 \pm 0.82$ & & \\
\hline \multirow{2}{*}{ Skill deficit } & Female & 16 & $3.79 \pm 0.61$ & \multirow{2}{*}{0.158} & \multirow{2}{*}{0.87} \\
\hline & Male & 71 & $3.76 \pm 0.61$ & & \\
\hline \multirow{2}{*}{ Rebelliousness and resistance } & Female & 16 & $3.42 \pm 0.86$ & \multirow{2}{*}{1.743} & \multirow{2}{*}{0.08} \\
\hline & Male & 71 & $3.0 \pm 0.86$ & & \\
\hline \multirow{2}{*}{ Disorganization } & Female & 16 & $2.98 \pm 1.25$ & \multirow{2}{*}{0.933} & \multirow{2}{*}{0.35} \\
\hline & Male & 71 & $2.72 \pm 0.92$ & & \\
\hline
\end{tabular}

\section{DISCUSSION}

The results obtained for the study of different factors of employees' procrastination revealed that the resistance, boredom due to task fulfillment, perfectionism, lastminute syndrome, lack of motivation for task, skill deficit and employees' rebelliousness are linked to their level of procrastination. In their study, Vehs \& Bavmayster concluded that procrastination is deemed as the ability for intensive control over the thoughts, emotions and performance conforming to the standards. ${ }^{10}$ The findings of this study were in line with those of Vehs \& Bavmayster. Accordingly, Steel in one study tried to examine the root reasons and possible effects of procrastination with numerous factors. Based on the results of his study, there is a trivial correlation between procrastination and neuroticism, rebelliousness and disobedience and impulsiveness. Furthermore, taskaversion, task delay, self-efficacy, conscientiousness, self-management forms, distraction, motivation for progress are among the reasons behind the procrastination..$^{18}$ In this line, Pullen in his research found that there was a significant correlation between perfectionism and overall scores obtained for the level of procrastination for writing the thesis and fear of failure and the annoyance of the activities. The most common feeling expressed by the subjects when thinking about their theses were divided into four modes including completely negative, completely negative, anxious and worried and negative feeling towards oneself. ${ }^{19}$ The results of this research conformed to those of Pullen's confirming each other.

The procrastination here discussed does not signify a natural and usual delay which sometimes occurs. Here, procrastination refers to a personality characteristic that disrupts the personal satisfaction hurting the quality of human relations. This type of procrastination can be termed chronic procrastination or "tomorrow syndrome". In Steel's opinion, the essence of this psychological disorder is putting off, and postponing the tasks to a future time and showing negligence in performing the task. ${ }^{19}$ As a result, procrastination finds meaning in both individual and collective affairs. Simpson \& Pykyl in their research assessed the association between procrastination, personality traits based on self-excitation and belief in procrastination motivators. As per the results of the analysis, general procrastination is a measure of excited procrastination and some believe that their procrastination is driven by significant excitation. ${ }^{10}$

Psychologists have studied procrastination from different perspectives both cognitive and behavioral presenting some treatment approaches and techniques for overcoming it. Regarding treatment, the following methods can be enumerated: attempt towards creating motivation and blocking laziness and indolence, avoiding rationalization, medical dictation, punishment and preventive conditioning, change of the environment, finding an organized friend, and lack of expectation for rapid progress and emotional method for overcoming the procrastination. Dewitte \& Schouwenburg reported that procrastination is closely related to the lack of perseverance and lack of ability in performing the tasks. In this research, the procrastinators often put off their plans at the cost recreational activities but they did not intend to decrease their study or defer it. The procrastinators seemed to be students who have a high motivation but lack the capability for preventing the temptations and fears which disrupt their concentration during their study. ${ }^{12}$ In this regard, Sutton states that the employees' participation can be very effective in their resistance towards change. Keshman regards the resistance to the change as the defense mechanism against fear of failure. According to him, if the man feels that change will lead to the demolition of his havings and current status, since the future is unknown for them, they will delimit their capabilities in their move towards such a future. ${ }^{20}$ Nevill showed that one of the stressful sources in the work place is work overload and lack of sufficient time for performing the tasks. However, what is important is the way the time is used. Time management in fact implies the efficient use of resources and the existing way for achieving the personal objectives and 
ambitions covering a group of skills including selfregulation, targeting, management of disruptions, the way of organization of the affairs etc. Such skills can eliminate many organizational stress resources and as a result, lower their negative effects. ${ }^{21}$

Given the findings of this research about the six factors, namely, the resistance of the employees towards performing the tasks, boredom, perfectionism as a personality trait, last-minute syndrome, lack of motivation for task and skill deficit. The effects o these factors have been confirmed in the procrastination observed among the university employees. It is necessary to make some measures for decreasing procrastination among the university's employees by clarifying the goals and delineating the task descriptions accurately for each employee, training and clarifying the optimum ways for completing the tasks, rewarding the active employees given their level of progress, creating a sense of respect and value for the employees, using time management in performing job tasks and improving the communicative networks within the organization both qualitatively and quantitatively.

\section{ACKNOWLEDGEMENTS}

This research is a product a cooperation between Shahrekord University of science and Azad University Dehaghan. We acknowledge all those who help us both technically and financially.

Funding: No funding sources

Conflict of interest: None declared

Ethical approval: Not required

\section{REFERENCE}

1. Dubrin AJ. Applied psychology: individual and organizational effectiveness. Prentice Hall. 2004.

2. Ellis A, Knaus W. Overcoming procrastination. New York: New American Library.2002.

3. Ellis A, Knaus WJ. Overcoming procrastination. New York: Institute for Rational Living. 1979.

4. Senecal C, Koestner R, Vallerand RJ. Selfregulation and academic procrastination. Journal of Social Psychology. 1995;135:607-19.

5. Ellis A, Knaus WJ. Overcoming procrastination. New York: Institute for Rational Living, 1979.

6. Warner R. Procrastination and How to Beat it, Center for Learning and Professional Development. 2009. The University of Adelaide SA, Australia. P.1,www.adelaide.edu.au/clpd.

7. Akinsole MK, Tella A. A Correllates of academic procrastination and mathematics achievement of university undergraduate students. Eurasia Journal of mathematics, Science \& Technology Eduation. 2007;(3):4:364.

8. Chu AC, Chol JN. Rethinking procrastination: Positive effects of active procrastination behavior on attitudes and performance. J Social Psychol. 2005:145;245-64.

9. Ferrari JR, Tice DM. Procrastination as a self handicap for men and women: A task avoidance strategy in a laboratory setting. J Res Personality. 2000:34;73-83.

10. Van WYKL. The relationship between procrastination and stress in the life of the high school teacher, university of Pretoria. 2004:84;3-23.

11. Gafni R, Ger N. Time Management: Procrastination Tendency in Individual and Collaborative Tasks, Interdisciplineary. Journal of information, Knowledge and Management. 2010:(5):116-23.

12. Dewitte S, Schouwenburg HC. Procrastination, and incentives: the struggle between the present and the future in procrastinators and the punctual, British Journal of Social Psychology. 2002;43(2):269-86.

13. Schwartz KR. Between today and tomorrow: Procrastination and subjectivity. Unpublished doctoral dissertation, Adelphi University, 2007.

14. Shafran R, Cooper Z, Fairburn CG. Clinial Perfectionism: coganitive behavior analysis. Journal Behavior Research and Terapy. 2002:40;773-91.

15. Flett GL, Hewith PL. Perfectionism: Theory, research, and treatment .Journal American Psychological Association: Washington, P.C., 2002.

16. Sirois FM. Procrastination and intentions to perform health behaviors: The role of self-efficacy and the consideration of future consequences. Personality and Individual Differences. 2004:37;115 -28.

17. Ekundayo HT, Knowea PE, Yusuf MA. Towards effective time management among lectures in nigerian universities, Journal of emerging trends in educational research and policy studies. JETERAPS. 2010;1(1):24.

18. Steel P. The nature of procrastination: a metaanalytic and theoretical review of quintessential self-regulatory failure. J Psychological bulletin. 2007;133(1):65-94.

19. Pullen, Janelle F. Perfectionism, procrastination, and other self - reported barriers to completing the doctoral dissertation. University of IOWA, 2003.

20. Sutton J. Avoid procrastination. Urges action now, not later. Ferrari, J. R., Jonson, J. L., \& McCown, W. G. Procrastination and task avoidance: Theory, research, and treatment. New York: Plenum Press, 2009.

21. Neville C. Procrastinatin: What it is. Why we do you. What we can do about it. Univesity of baradford, School of management, 2007.

Cite this article as: Boldaji MK, Shirvani A, Sharifi-Rad J, Raeisi H, Rastar AA, Mirzaeian R. Examination of causes behind procrastination among Shahrekord University of Medical Sciences employees and proposing some strategies for their preventing: A study using the Van Wyk's Model. Int J Res Med Sci 2015;3:1657-61. 